\title{
Impact of Air Pollution on Public Health
}

\author{
E. Marchwinska-Wyrwal1,2, G. Dziubanek ${ }^{1}$, I. Hajok ${ }^{1}$, \\ M. Rusin ${ }^{1}$, K.Oleksiuk $^{1}$ and M.Kubasiak ${ }^{1}$ \\ ${ }^{1}$ Department of Environmental Health, Medical University of Silesia, Katowice \\ ${ }^{2}$ University of Ecology and Management, Warsaw \\ Poland
}

\section{Introduction}

The air we breathe contains emissions from many different sources: industry, motor vehicles, heating and commercial sources, household fuels as well as tobacco smoke. The effects of air pollution on health have been intensively studied in recent years. The results of these studies showed that air pollution harms human health and particularly is harmful for those who are already vulnerable because of their age as children and older people or existing health problems. The epidemiological evidence suggests that adverse health effects are dependent on both exposure concentrations and length of exposure, and that long-term exposures have larger, more persistent cumulative effects than short-term exposures [1]. Ambient air pollution has been associated with a multitude of health effects, including mortality, respiratory and cardiovascular hospitalizations, changes in lung function and asthma attacks. Current scientific evidence indicates that air pollution from the combustion of fossil fuels causes a spectrum of health effects from allergy to death. Recent assessments suggest that the public health impacts may be considerable. Air pollution is associated with a broad spectrum of acute and chronic health effects, the nature of which may vary depending on constituent of the pollutants as well as the group of the population. Current exposure to PM from anthropogenic sources leads to the loss of 8.6 months of life expectancy in Europe - from around 3 months in Finland to more than 13 months in Belgium. The most recent estimates of impacts of PM on mortality, based on $\mathrm{PM}_{10}$ and $\mathrm{PM}_{2.5}$ monitoring data in 40 European countries, indicate that close to 500000 deaths per year are accelerated due to exposure to ambient PM in those countries. According to the WHO Health Reports, air pollution at current levels in European cities is responsible for a significant burden of deaths, hospital admissions and exacerbation of symptoms, especially for cardiovascular disease. Because of the tremendous number of people affected, the impact of air pollution on cardiovascular disease represents a serious public health problem. Results from research studies have demonstrated a strong relationship between levels of airborne particles, sulfur dioxide and other fossil fuel emissions and risk of early death from heart disease. People with pre-existing conditions such as high blood pressure, previous heart disease, diabetes, respiratory disease and high cholesterol have been shown to be especially vulnerable. The results of a long-term study on influence of common air pollutants on health of US residents showed that individuals living in the more polluted cities had a higher risk of hospitalization and early death from pulmonary and heart 
diseases as compared to those living in the less polluted cities. The study focused on the health effects of gaseous pollutants such as sulfur dioxide, which are produced mainly by coal-burning power plants and fine particle air pollution, particles with a diameter of less than $2.5 \mu \mathrm{m}$, that come from power plant emissions and motor vehicle exhaust. The relationship between air pollution and mortality was much stronger for the fine particle component than for the gaseous pollutants. Exposure to PM is associated with increased hospital admissions and mortality in adults. The risk increases linearly with the concentration of pollution and there is no evidence to suggest a threshold for PM below which no adverse health effects would occur. When inhaled, $\mathrm{PM}_{10}$ particles (with a diameter of less than $10 \mu \mathrm{m}$ ) penetrate deep into the respiratory system. Finer particles (with a diameter of less than $2.5 \mu \mathrm{m}$ ) then go on to penetrate the lungs and pass into the bloodstream and are carried into other body organs. Concerned that these particles cause a wide range of health impacts, WHO has developed guidelines addressing their risks. Knowledge about the links between health and air quality has significantly advanced in the last years. It was determined that short-term exposure to $\mathrm{PM}_{2.5}$ significantly increases the risk for cardiovascular and respiratory disease among people over 65 years of age. In the U.S. the National Morbidity, Mortality and Air Pollution Study indicated a $0.41 \%$ increase in total mortality in response to a $10-\mu \mathrm{g} / \mathrm{m}^{3}$ increase in $\mathrm{PM}_{10}$ in ambient air [2]. The investigators linked $\mathrm{PM}_{2.5}$ data to hospital admissions for heart and vascular diseases, heart failure, chronic obstructive pulmonary disease and respiratory infections in an epidemiologic study of over 11.5 million Medicare participants. The study results predict that for each 100 hospital admissions for heart failure, one extra admission will occur for each $10 \mu \mathrm{m} / \mathrm{m}^{3}$ increase in $\mathrm{PM}_{2.5}$ [2].

New studies also indicate substantial gains in public health resulting from improvements in air quality. An improvements in air quality over the last 20 years have increased average life expectancy in the U.S. by approximately five months. Researchers at Brigham Young University and the Harvard School of Public Health tracked particulate matter air pollution in 51 major metropolitan areas from 1978 through 2001 and compared those data to death records and census data. On average, life expectancy increased by 2.72 years with about $15 \%$ of that increase due to improved air quality. Cities that had the greatest air quality improvements saw the greatest gains in life expectancy. The results shows that a reduction of $10 \mu \mathrm{g} / \mathrm{m}^{3}$ in the ambient air concentration of particulate matter was associated with an estimated increase in average life expectancy of 0.61 years [3]. The magnitude of changes in the health state of population in the polluted part of Poland has been estimated in assuming that the ambient air pollution decrease is $10 \%$ [4]. In the case of cardiovascular diseases, a $10 \%$ reduction of lead concentration in the air will cause a decrease in the incidence by 17.6 cases per 10000 people. A $10 \%$ reduction of cadmium concentration in the air may result in a decrease in neoplasm mortality by more than 4 cases per 10000 inhabitants. The reduction of the concentrations of both heavy metals in the air will lower SDR; in the case of cadmium by 24.4 , and in the case of lead by 31.6 people. The time scale over which the health effects develop is under investigation. Particulate air pollution is consistently related to the most serious effects, including lung cancer and other cardiopulmonary mortality. Long-term average exposure to PM is associated with both the risks of chronic effects on children's health, such as impaired development of lung function, and the frequency of acute effects, such as the aggravation of asthma or incidence of respiratory symptoms. Children who live in neighborhoods with serious air pollution problems (emissions from the automobile 
traffic, heavy industry) have lower IQ and score worse memory tests than children from the cleaner environments. The respiratory and cardiovascular effects of air pollution are well documented; however the possible neurodegenerative effects of air pollution have been unexplored and require further intensive research. The research in the US showed that the more heavily exposed children were to black carbon, the lower their scores on several intelligence tests. For example, the average IQ of the most heavily exposed children was 3.4 points less than children with low exposure. When the findings were adjusted for the effects of parents' education, birth weight, and exposure to tobacco smoke, the associations remained. The effects were roughly equivalent to those seen in children whose mothers smoked ten cigarettes per day while pregnant. The researchers assumed that the harmful effects may be caused by the inflammatory and oxidative effects of the black carbon particles [5]. These findings suggest additional research is needed to investigate the effects of air pollution on the development of intelligence in children and on cognitive decline for people of all ages. Globally, the prevalence of asthma and allergies has increased over the last few decades. Asthma has become the commonest chronic disease in children and is one of the major causes of hospitalization for children aged under 15 years. The increasing prevalence of allergic diseases in children throughout Europe is no longer restricted to specific seasons or environments. It has only become fully apparent in the last decade that air pollution, especially of fine particulates, plays a major role in cardiovascular disease. A half of deaths globally arises from cardiovascular disease. Even relatively small increases in the risk of cardiovascular disease will translate into huge numbers of additional people suffering more severely from the disease. There is now substantial evidence concerning the adverse effects of air pollution on pregnancy outcomes and infant death. Evidence reporting associations between maternal exposure to ambient air pollutants and adverse fetal development, in particular growth restriction, pre-term birth, and infant survival due to postnatal respiratory mortality has been growing rapidly in recent years. The association between maternal exposure to ambient air pollution and the risk of congenital anomalies, which are a significant cause of stillbirth and infant mortality has been less well studied. New evidence is also accumulating on the burden of disease due to indoor air pollution. The air pollutants such as asbestos fibers and dioxins, resulting from waste disposal, has been associated with a multitude of health effects. Asbestos fibers are dangerous to health and practically indestructible. Human exposure to asbestos fiber found in inhaled air can lead to diseases such as chronic bronchitis, asbestosis, lung cancer and mesothelioma. The World Health Organization officially recognized asbestos as a carcinogen that pollute the environment globally. It starts a process of gradual elimination of asbestos from the human environment. The building asbestos stripping operations and waste disposal, because of higher emission of asbestos fibers into environment, puts human population at enormous risk. European Union experts estimate that asbestos-related cancers will cause approximately 500000 deaths up to the year 2030 in Western Europe alone. Dioxin and related compounds always exist in nature as complex mixtures. Dioxins are widely distributed in the environment at low concentrations, primarily as a result of air transport and deposition. Emissions of polychlorinated dibenzodioxin and dibenzofuran (PCDD/F) result from inefficiencies of combustion processes, most typically waste combustion. For uncontrolled combustion, such as open burning of household waste, chlorine content of wastes may play the most significant role in levels of dioxin emissions. Dioxin and related compounds have been shown to be developmental, reproductive, immunological, endocrinological, and cancer hazards, among others in multiple animal species. There is no reason to expect, in general, 
that humans would not be similarly affected at some dose, and an increasing numbers of data supports this assumption. Tetrachlorodibenzo- $p$-dioxin (TCDD) is best characterized as "carcinogenic to humans." This means that, on the basis of the weight of all of the evidence (human, animal, mode of action), TCDD meets the criteria that allow the scientific community to accept a causal relationship between TCDD exposure and cancer hazard.

\section{Human exposure to air pollution: The route of air pollutants to a human organism}

Air pollution is a mixture of particulate matter (PM), gases, and vapor-phase molecules [6]. The direct rout of exposure to the air pollution is a respiratory tract. In case of dust pollutants the size of particulate matter is playing an important role in the environmental health risk. PM is categorized by aerodynamic diameter. Particles below $10 \mu \mathrm{m}$ in diameter are classified as thoracic particles $\mathrm{PM}_{10}$, particles below $2.5 \mu \mathrm{m}$ in diameter as fine particles, and particles with a diameter $<0.1 \mu \mathrm{m}$ as ultrafine particles (UFPs) [6]. Particles larger than $10 \mu \mathrm{m}$ are likely to land in proximal airways, but fine particles reach the lungs and are deposited in the alveoli [7]. Therefore $\mathrm{PM}_{2.5}$ may be more harmful than larger ones [8]. Ambient fine particulate pollution was associated with increased risk of cardiovascular diseases [9]. UFPs are deposited deeply into the lungs. The study of Terzano et al. (2010), indicates that the ultrafine particles in contrast to larger-sized particles pass into the bloodstream by different transfer routes and mechanisms and then are distributed into other body organs, including the brain with potential neurotoxic effects [10]. The particulate matter is hazardous to the human health due to absorption on their surface of many harmful contaminants such as: heavy metals (lead, cadmium, mercury and the other), organic compounds (polycyclic aromatic hydrocarbons, PCBs, dioxin and furans). Gaseous pollutants, depending on their solubility in the water, are absorbed in the proximal or the distal parts of the respiratory tract. This is important from the standpoint of the health effects. Sulfur dioxide and formaldehyde are highly water-soluble gases, therefore they do not reach the lungs, and they are irritating the airway epithelium of the upper respiratory tract. For example up to $98 \%$ sulfur dioxide may be absorbed in the nasopharynx during nasal breathing [11]. $\mathrm{NO}_{2}$ is a poorly water-soluble gas, therefore, is deposited far more peripherally in a respiratory tract compared with $\mathrm{SO}_{2}$, but does not reach the alveoli in any significant quantities [11]. Ozone, in contrast to nitrogen dioxide, does not dissolve in water and in gaseous form reaches the lungs where it begins its malicious activity. Gaseous pollutants can be also absorbed into the bodythrough dermal rout of exposure. However for the general population the role of this route of exposure is insignificant. The indirect rout of exposure to the air pollutants is digestive tract; it follows from the circulation of pollutants in the environment. The food chain is an important pathway of human exposure to polycyclic aromatic hydrocarbons, dioxin, PCBs and heavy metals (cadmium, lead, mercury).

\section{Relation between air pollution and life expectancy (LLE)}

The World Health Organization has identified ambient air pollution as a high public health priority, indicating the relationship of air pollution with increased mortality and shortened life expectancy [12]. In 2009, life expectancy at birth in twenty seven countries in the European Union [EU-27] was among the highest in the world - almost 76 years for men 
and 82 years for women [13,14]. In Europe there is a wide variety of life expectancy. In developed countries, located mainly in the western part of Europe and the Nordic countries, people live a few years longer than in the countries of Central and Eastern Europe and these differences are even a dozen years. According to EU experts, current exposure to PM from anthropogenic sources reduces the average life expectancy of 8.6 months in Europe - from around 3 months in Finland and Ireland to more than 13 months in Belgium [15]. It has been estimated that exposure to fine particulate matter in outdoor air leads to 725000 years of life lost annually in Europe [16,17]. Studies in the USA have shown that people from less polluted cities live longer than those living in more polluted cities. After adjustment for other factors, an association remained between ambient annual average concentrations of fine particles (represented by $\mathrm{PM}_{2.5}$ ) and age-specific risks of mortality, implying shorter life expectancy in more polluted cities [18]. It is estimated that in the European Union an increase of $1 \mu \mathrm{g} / \mathrm{m}^{3}$ of $\mathrm{PM}_{2.5}$ for 1 year implies an average Lost of Life Expectancy (LLE) of 0.22 days per person; the number for the United States is similar, but for Russia it is about $40 \%$ higher, and for China it is about $25 \%$ lower [19]. A study published in 2009, conducted in 51 U.S. metropolitan areas between 1970 to 2000 showed that decrease of $10 \mu \mathrm{g} / \mathrm{m}^{3}$ in the concentration of fine particulate matter was associated with an estimated increase of average life expectancy of 0.61 year. The estimated effect of reduced exposure to pollution on life expectancy was not highly sensitive to adjustment for changes in socioeconomic, demographic, or proxy variables for the prevalence of smoking or to the restriction of observations to relatively large counties [3]. The other studies have shown that reductions in life expectancy of 1.11 years in the Netherlands, 1.37 years in Finland, and 0.80 year in Canada resulting from increases in ambient $\mathrm{PM}_{2.5}$ concentrations of $10 \mu \mathrm{g} / \mathrm{m}^{3}$ [20,21]. Longterm exposure to PM is particularly damaging to human health and reduces life expectancy, that is why reducing long-term PM concentrations and exposure is a priority [21,22].

\section{Relation between air pollution and mortality}

Air pollution is a major environmental risk for health and is estimated to cause approximately 2 million premature deaths worldwide per year. PM air pollution imparts a tremendous burden to the global public health, ranking it as the 13th leading cause of morality [23]. The estimates of health effects of PM exposure in adults are dominated by the increase in the risk of mortality due to long-time exposure to fine PM $\left(\mathrm{PM}_{2.5}\right)$ The total number of premature deaths attributed to exposure amounts to around 348000 annually in the 25 EU countries. More than half of the burden from air pollution on human health is borne by people in developing countries $[15,24]$. The short-term health effects of particulate and gaseous air pollutants have been well documented, mainly through time-series studies relating short-term elevations in ambient levels of such pollutants to increases in morbidity and mortality from cardio respiratory conditions. Results of 124 studies of the largest cities in North America and Europe showed an increase in the rate of death from any cause ranging from 0.2 to $0.6 \%$ for an increase in ambient $\mathrm{PM}_{10}$ concentrations of $10 \mu \mathrm{g} / \mathrm{m}^{3}$ [25]. Long-term epidemiological studies conducted in the U.S. confirm that the adverse effects of fine particulate matter $\left(\mathrm{PM}_{2.5}\right)$ on morbidity and mortality, and indicate that this effect depends on the concentration and time of exposure; long-term exposure gives higher effects than short-term exposure [26]. Long-term exposure to $\mathrm{PM}_{2.5}$ increases the risk of no accidental mortality by $6 \%$ per a $10 \mu \mathrm{g} / \mathrm{m}^{3}$ increase, independent of age, gender, and geographic region. Exposure to PM was also associated with an increased risk of mortality 
from lung cancer (range: $15 \%$ to $21 \%$ per a $10 \mu \mathrm{g} / \mathrm{m}^{3}$ increase) and total cardiovascular mortality (range: $12 \%$ to $14 \%$ per a $10 \mu \mathrm{g} / \mathrm{m}^{3}$ increase) [1,27]. The Medicare Cohort Air Pollution Study in the USA has estimated the relative risk of death associated with longterm exposure to $\mathrm{PM}_{2.5}$. According to the authors Zeger et al. [28], a $10 \mathrm{mg} / \mathrm{m}^{3}$ increase in six year average of $\mathrm{PM}_{2.5}$ is associated with a $6.8-13.2 \%$ increase in mortality. Other studies [27] showed that long-term exposure to $\mathrm{PM}_{2.5}$ increases the risk of non-accidental mortality by $6 \%$ per a $10 \mathrm{mg} / \mathrm{m}^{3}$ increase, independent of age, gender, and geographic region. Exposure to $\mathrm{PM}_{2.5}$ was also associated with an increased risk of mortality from lung cancer (range: $15-21 \%$ per a $10 \mathrm{mg} / \mathrm{m}^{3}$ increase) and total cardiovascular mortality (range: $12-14 \%$ per a $10 \mathrm{mg} / \mathrm{m}^{3}$ increase) [27]. People with diabetes, heart failure, chronic obstructive pulmonary disease (COPD) and inflammatory diseases such as rheumatoid arthritis are at increased risk of death when they are exposed to particulate air pollution, or soot, for one or more years. Increase of $10 \mu \mathrm{g} / \mathrm{m}^{3}$ of $\mathrm{PM}_{10}$ over 2 years increased the risk of death by $32 \%$ for patients with diabetes, by $28 \%$ for patients with COPD, by $27 \%$ for patients with congestive heart failure, and by $22 \%$ for people with inflammatory diseases such as rheumatoid arthritis or lupus [29]. Significant associations were found between black smoke (BS) and $\mathrm{SO}_{2}$ concentrations and mortality. The effects were stronger for respiratory illness than other causes of mortality for the most recent exposure periods (shorter latency times) and most recent mortality period (lower pollutant concentrations) [30]. Air pollution has long-term effects on mortality and point to continuing public health risks. They therefore have importance for policies on public health protection through regulation and control of air pollution [30].

\section{The impacts of fine particulate matter on cardiovascular health}

Cardiovascular disease (CVD) constitute a global problem and is the leading cause of death in the world, especially in highly developed countries. Cardiovascular disease is also a major cause of disability and of reduced quality of life [31,32]. According to forecast, almost 20 million people will die from CVDs, mainly from heart disease and stroke by 2015 [33,34]. Results from many research studies have demonstrated a strong relationship between levels of airborne particles, sulfur dioxide and other air pollutants and risk of early death from heart disease. Air pollutants have been linked with endothelial dysfunction and vasoconstriction, increased blood pressure (BP), prothrombotic and coagulant changes, systemic inflammatory and oxidative stress responses, autonomic imbalance and arrhythmias, and the progression of atherosclerosis [35].

Using data for Chicago area hospitals for years 1988 to 1993 it was found, that an increase in $\mathrm{PM}_{10}$ level by $10 \mu \mathrm{g} / \mathrm{m}^{3}$ was associated with $1.27 \%, 1.45 \%$, and $2 \%$ increases in hospital admissions for heart disease, chronic obstructive pulmonary disease, and pneumonia, respectively [36]. The Air Pollution and Health: a European and North American Approach (APHENA) project also examined the association between airborne particles and hospital admission for cardiac causes in eight European cities and found that the percentage increases associated with a $10 \mu \mathrm{g} / \mathrm{m}^{3}$ elevation in $\mathrm{PM}_{10}$ were $0.5 \%$ for cardiac admissions in people of all ages and $0.7 \%$ for cardiac admissions in people older than 65 years $[37,38]$. Short-term exposure to $\mathrm{PM}_{2.5}$ significantly increases the risk for cardiovascular and respiratory disease among people over 65 years of age. The investigators linked $\mathrm{PM}_{2.5}$ data to hospital admissions for heart and vascular diseases, heart failure, chronic obstructive pulmonary disease, and respiratory infections in an epidemiologic study of over 11.5 million 
Medicare participants. The study results predict that for each 100 hospital admissions for heart failure, one extra admission will occur for each $10 \mu \mathrm{g} / \mathrm{m}^{3}$ increase in $\mathrm{PM}_{2.5}$ [2]. People with pre-existing cardiovascular disease, diabetic and elderly individuals are also considered to be more susceptible to air pollution-mediated cardiovascular effects [39].

Long-term exposure to elevated concentrations of ambient $\mathrm{PM}_{2.5}$ at levels encountered in the present-day environment (i.e. any increase by $10 \mu \mathrm{g} / \mathrm{m}^{3}$ ) reduces life expectancy within a population probably by several months to a few years [40]. As $\mathrm{PM}_{2.5}$ is most strongly associated with cardiovascular deaths in the cohort studies, the reduced life expectancy is most likely predominantly due to excess cardiovascular mortality [40]. It was found that the greater the level of the fine particulate pollution, the greater the risk of cardiovascular disease and death in post-menopausal women, who are considered to be susceptible group within the general population. The increased risk comes from the fine particulate matter typically produced by automobile exhaust. The particles damage arteries in the heart and brain. Even slight elevations in fine particulate matter concentration increased the risk significantly. The risk of dying from heart attack or stroke increased $76 \%$ for each ten microgram increase in fine particulate pollution and proved to be about three times higher than previously estimated [41]. The study also indicates that although smoking is a much larger risk factor for cardiovascular disease, exposure to fine particulate combined with smoking imposes additional effects [42]. Additional research is required to establish whether there are independent health effects of the other particulate size fractions beyond those posed by fine particles. Although the focus of the present statement is on PM, it is recognized that other air pollutants may also pose cardiovascular risk alone or in conjunction with fine-particle exposure [40]. There are some evidences that gaseous pollutants may also be a reason for hospitalizations. Hospital admissions for cardiovascular causes, particularly ischemic heart disease, were found to rise in relation to the previous-day and same-day level of $\mathrm{SO}_{2}$, even after adjustment for $\mathrm{PM}_{10}$ levels [40].

Although ozone has been linked to increased cardiopulmonary mortality, strokes, and MIs in some short-term studies, long-term exposure was not associated with cardiovascular mortality after accounting for PM in a recent analysis. The recent finding that small changes in low levels of ambient carbon monoxide concentrations are related to cardiovascular hospitalizations also requires further study [40]. Several secondary aerosols (eg, nitrate and sulfate) are often associated with cardiovascular mortality; however, whether these compounds are directly harmful or are surrogate markers of toxic sources of exposure requires more investigation [40]. The results showed that the daily number of hospitalizations for cardiovascular diseases was significantly associated with daily $\mathrm{PM}_{10}$ and $\mathrm{NO}_{2}$ levels, with stronger associations in the elderly ( $\geq 65$ years of age) [43]. During the last 15 years air pollution induced cardiovascular toxicity has become the focus of intensive studies among cardiologists and specialists in environmental medicine. They found that long-term particulate matter exposures were most strongly associated with death due to ischemic heart disease, dysrhythmias, heart failure, and cardiac arrest. For these causes of death, a $10 \mu \mathrm{g} / \mathrm{m}^{3}$ elevation in particulate matter was associated with $8 \%$ to $18 \%$ increases in mortality risk. Risks for smokers were comparable or larger than for non-smokers. The researchers conclude that particulate matter exposure is a risk factor for specific cardiovascular disease mortality through mechanisms that likely include pulmonary and systemic inflammation, accelerated atherosclerosis, and changes in cardiac rhythms [42]. According to more recent studies, the ultrafine particles may be translocated into the 
circulation and directly transported to the vasculature and heart where they can induce cardiac arrhythmias and decrease cardiac contractility and coronary flow [39]. Improving our understanding of the biological mechanisms underlying the acute cardiovascular effects of air pollution is essential to define the best prevention strategies [37]. Cardiovascular disease is very common and, as exposure to air pollution, both in the long and short term, contributes to initiation and exacerbation of disease, it is likely that even modest reductions in exposure will result in significant health gain [43].

\section{The adverse effects of air pollution on pregnancy outcomes and infant death}

In the last two decades there is observed an increase of the number of scientific reports about a proven influence of air pollution on an occurrence of negative health effects, connected with births. They are: preterm births, stillbirths, intrauterine fetus growth retardation, births of newborns with low birth weight and a risk of newborns' death because of respiratory system disorders [44,45]. Birth weight, gestational age, and fetal growth are important indicators of perinatal health. Low birth weight (LBW), preterm birth, or intrauterine growth retardation (IUGR) are strongly association with infant mortality and morbidity [46]. Long term study shows that low birth weight (LBW) is a risk factor for developing in adulthood coronary health diseases, hypertension and type 2 diabetes [45]. It was observed up to $20 \%$ increase in risk of LBW and preterm birth in infants born to women leaving in area with high level of air pollution, specially those exposed to higher levels of motor vehicle exhaust pollution coming from heavy-traffic roadways. Stronger effects were observed for women whose third trimester accounted for months with cold weather, when concentration of air pollutants was the highest because of an activity of local heating sources [47]. In heavily polluted environments the prematurity rate (birth before the $37^{\text {th }}$ week of pregnancy) increases considerably. The study done in the 90 's, in the most polluted parts of Poland (Chorzow) shows as high as 14 to $20 \%$ of the prematurity rate comparing to $8 \%$ rate for Poland this time. The average newborns' birth weight was 515g lower in Chorzow than in the Country [48]. There are more evidence each year which indicate that maternal exposures to air pollutants, including particulate matter (aerodynamic diameter $10 \mu \mathrm{m}$ and $2.5 \mu \mathrm{m})$, sulfur dioxide, nitrogen dioxide and benzopyrene, are associated with adverse pregnancy outcomes [49]. Some of polycyclic aromatic hydrocarbons (PAHs), especially benzopyrene, prove carcinogenic and mutagenic effects and when penetrating through placenta, have a negative influence into fetus. The research showed the newborns, whose mothers were exposed to PAHs during pregnancy, more often born with lower birth weight and smaller head circumference [50, 51, 52]. According to Dejmek et al. (2000), the risk of delivering a growth-retarded infant increases with the level of PAHs in early gestation (first month) [53]. A bond of benzopyrene and DNA in the placenta, has an influence on intrauterine growth retardation - IUGR $[54,55]$. The exposure to particulate matter (PM) causes increase of risk of occurrence an intrauterine fetus growth retardation $[56,57,58]$. Children, whose mothers were exposed to high concentrations of PM during pregnancy, more often were born with low birth weight and $10 \mu \mathrm{g} / \mathrm{m}^{3}$ change in $\mathrm{PM}_{10}$ accounted for 13.7 $\mathrm{g}$ less of weight $[59,60,61]$. Effect of mothers' exposure to high concentration (above the median $\left.36.3 \mu \mathrm{g} / \mathrm{m}^{3}\right)$ of fine particles $\left(\mathrm{PM}_{2,5}\right)$ was reflected in significantly lower mean weight $(128.3 \mathrm{~g})$ and length $(0.9 \mathrm{~cm})$ and lower mean head circumference $(0.3)$ of newborns 
[62]. The researchers in the USA found that mothers who lived in areas with the highest levels of $\mathrm{PM}_{2.5}$ during their pregnancy delivered slightly smaller babies than their counterparts who lived in areas with lower levels of $\mathrm{PM}_{2.5}$ exposure. They also observed association between number of traffic-related pollutants and small for gestational birth weight as well as preterm births (before 37 weeks) [63,64]. Maternal exposure to sulfur dioxide during the first month of pregnancy increased risk of intrauterine growth retardation as well as LBW when preterm birth was associated with exposure to $\mathrm{SO}_{2}$ during the last month of pregnancy. These results suggest an association between VLBW (below $1500 \mathrm{~g}$ ) and maternal exposures to high levels of sulfur dioxide $[46,60]$. Increased risk of intrauterine growth retardation was observed also in case of maternal exposure to nitrogen dioxide during the first month of pregnancy [65]. An association between exposure to levels of nitrogen dioxide above $40 \mu \mathrm{g} / \mathrm{m}^{3}$ during the first trimester of pregnancy and a reduction in birth weight was found [66]. Study on CO influence on pregnancy [67] were the basis for estimation that one unit change in mean $\mathrm{CO}$ concentration during the last trimester of pregnancy increases the risk of low birth weight by $8 \%$. Furthermore, a one unit change in mean $\mathrm{CO}$ concentration during the first 2 weeks after birth increases the risk of infant mortality by $2.5 \%$ relative to baseline levels [67].

\section{Human's exposure to air pollution resulting from waste disposal}

Asbestos is a mineral fiber that due to the unique physical and chemical properties was produced in the past and used in over 3000 products. In the $20^{\text {th }}$ century, asbestos has dominated the building industry, with a maximum global production of 5 million tonnes per year. As a result, the world's asbestos (in products) is currently estimated at around 550 million tonnes. Asbestos fibers are indestructible and dangerous to health. Human exposure to mineral fiber found in inhaled air can lead to diseases such as chronic bronchitis, asbestosis, lung cancer and mesothelioma [68]. International Agency for Research on Cancer (IARC) recognized asbestos (actinolite, amosite, anthophyllite, chrysotile, crocidolite, tremolite) as Group I carcinogen [69]. This category is used when there is sufficient evidence of carcinogenicity in humans. In 1980, the US National Institute of Occupational Safety and Health (NIOSH) and the Occupational Safety and Health Administration (OSHA) working group concluded that there are no levels of exposure to asbestos below which clinical effects did not occur [70]. In the 80's of the past century, the World Health Organization officially recognized asbestos as a carcinogen that pollutes the environment globally. Environmental exposure either in the houses of asbestos workers or in the neighborhood of asbestos mines or factories has been noted in some of the cases [71]. It has been estimated that a third of the mesotheliomas occurring in the USA may be due to nonoccupational exposure [72]. The relationship between asbestos exposure and smoking indicates a synergistic effect of smoking with regard to lung cancer [69]. Further evaluations indicate that this synergistic effect is a multiplicative model [73]. Exposure to asbestos occurs through inhalation of fibers from contaminated air in the working environment, as well as from ambient air in the vicinity of point sources, or indoor air in housing and building containing asbestos materials [74]. Although, in many countries the production and utilization of asbestos-containing materials has been banned, the numerous active environmental sources still exist [70]. Exposure can also occur during installation and use of asbestos-containing products and maintenance of vehicles. Asbestos products are still in place in many buildings and continue 
to give rise to exposure during use, maintenance, renovation, repairs, removal and demolition [74]. The results of environmental concentrations of respirable asbestos fibers show a wide range of values. The observed discrepancy in the concentrations are dependent on the different environments, specific sampling locations and presence of more than one emission sources [70]. Unfortunately, in recent years, emissions of asbestos fibers into the urban environment has significantly intensified. This follows from the fact that the durability of asbestos-cement building products is estimated for 30 years and the possibility of exploitation of these used in the 70's and 80's of the past century is coming to an end. As is apparent from analysis the deterioration of asbestos-containing construction materials, such as asbestos-cement sheets (AC) used in residential and industrial buildings causes additional contamination of the urban environment. The study performed in a highly urbanized and densely populated town in south part of Poland, revealed that asbestos fibers identified in the air samples near buildings covered with AC panels derived from 2 groups of asbestos minerals, i.e. crocidolite and chrysotile. The observed concentrations of respirable asbestos fibres varied from $0.0010-0.0090 \mathrm{f} / \mathrm{cm}^{3}$. Significantly higher values were noted in the immediate vicinity of the buildings with asbestos-containing materials, compared to sampling sites located at a distance of $100-500 \mathrm{~m}$ from such buildings or the sites treated as an asbestos free [70]. Kovalevskiy and Tossavainen, taking measurements near a building with asbestos-containing materials in Moscow, showed that when outdoor concentrations reach the level of $0.009 \mathrm{f} / \mathrm{cm}^{3}$, at the same time, indoor concentrations approach $0.049 \mathrm{f} / \mathrm{cm}^{3}$ in residential premises, or even $0.57 \mathrm{f} / \mathrm{cm}^{3}$ if the building was undergoing renovation [75]. The measurements of respirable fibers in the air on the playgrounds in housing estates, where path was made with admixture of asbestoscontaining material showed contamination range from $0.165-0.54 \mathrm{f} / \mathrm{m}^{3}$ and in apartments adjacent to the playground around $0.01 \mathrm{f} / \mathrm{m}^{3}$ [76]. The significant increase in concentrations of asbestos also recorded in the immediate vicinity of buildings, at which work is ongoing disassembly of asbestos-cement facades or roofing. The work conducted by a specialized company working according to safety regulations causing dust in the workplace ranged from 1000 to $4000 \mathrm{f} / \mathrm{m}^{3}$, while the same work done improperly can lead to maximum levels of respirable asbestos fibers in the amount of $80000 \mathrm{f} / \mathrm{m}^{3}$ [77]. Starting from the last decade of the $20^{\text {th }}$ century, the world began a process of gradual elimination of asbestos, what in fact results the higher emission of asbestos fibers into the municipal environment. The individual disassembly of utilized asbestos panels, not obeying safe methods of removal, storage, transport and treatment of asbestos waste intensify the environmental exposure of the general population. Since 1980, the number of deaths caused by exposure to asbestos fibers increases gradually, even in countries that have banded the use of asbestos in the early 1990s [78]. Currently about 125 million people in the world are exposed to asbestos at the workplace and at least 90000 people die each year from asbestos-related lung cancer, mesothelioma and asbestosis resulting from occupational exposures. In addition, it is believed that 7000 of deaths can be attributed to asbestos-related diseases as well as to nonoccupational exposures to asbestos [74]. The Report of UN EWG shows that in the U.S. each day 30 people die, which represents 10000 deaths per year only as a result of diseases caused by exposure to asbestos [79]. Because of long latency periods attached to the diseases, stopping the use of asbestos now will result in a decrease in the number of asbestos-related deaths after a number of decades [74]. It is estimated that in the next 40 years asbestos fibers will cause the death of about 100000 Americans [79]. European Union 
experts estimate that the total number of deaths caused by asbestos-related diseases in the UK, Belgium, Germany, Switzerland, Norway, Poland and Estonia is around 15000 annually; only in Western Europe asbestos-related diseases will caused 500000 deaths subsequent till the end of 2030 [80]. Considering the numerous health hazards resulting from the inhalation of asbestos dust, there is no safe environmental level for his harmful factor, therefore, the exposure should be kept as low as possible [70].

\section{References}

[1] Pope C.A. $3^{\text {rd }}$. Mortality effects of longer term exposure to fine particulate air pollution: Review of recent epidemiological evidence. Inhal Toxicol. 2007, 19(Suppl. 1):33-38.

[2] Dominici F., Peng R.D., Bell M.L., Pham L., McDermott A., Zeger S.L., Samet J.M. Fine particulate air pollution and hospital admission for cardiovascular and respiratory diseases. JAMA. 2006 Mar 8;295(10):1127-34.

[3] Pope CA 3rd, Ezzati M., Dockery D.W. Fine-particulate air pollution and life expectancy in the United States. N Engl J Med. 2009 Jan 22;360(4):376-86.

[4] Marchwinska-Wyrwal E., Dziubanek G., Skrzypek M., Hajok I.. Study of the health effects of long-term exposure to cadmium and lead in a region of Poland. Int J Environ Health Res. 2010 Apr;20(2):81-6.

[5] Suglia S.F., Gryparis A., Wright R.O., Schwartz J., Wright R.J.. Association of black carbon with cognition among children in a prospective birth cohort study. Am J Epidemiol. 2008 Feb 1;167(3):280-6.

[6] Brook R.D., Franklin B., Cascio W., Hong Y., Howard G., Lipsett M., et al. Air pollution and cardiovascular disease: a statement for healthcare professionals from the expert panel on population and prevention science of the American Heart Association. Circulation 2004; 109:2655-71.

[7] Kim, C.S., Fishe.r, D.M., Lutz., D.J., Gerrity, T.R., 1994. Particle deposition in bifurcating airway models with varying airway geometry. J. Aerosol. 25, 567-581

[8] Farina F., Sancini G., Mantecca P, Gallinotti D., Camatini M., Palestini P. The acute toxic effects of particulate matter in mouse lung are related to size and season of collection. Toxicol Lett. 2011 Mar 1. [Epub ahead of print]

[9] Pope C.A. 3rd,Muhlestein J.B., May H.T., Renlund DG, Anderson J.L., Horne B.D. Ischemic heart disease events triggered by short-term exposure to fine particulate air pollution. Circulation. 2006 Dec 5;114(23):2443-8. Epub 2006 Nov 13.

[10] Terzano C., Di Stefano F., Conti V., Graziani E., Petroianni A. Air pollution ultrafine particles: toxicity beyond the lung. Eur Rev Med Pharmacol Sci. 2010 Oct;14(10):80921.

[11] Sandström T. Respiratory effects of air pollutants: experimental studies in humans. Eur Respir J, 1995, 8, 976-995

[12] Samet J, Krewski D. Health effects associated with exposure to ambient air pollution. J Toxicol Environ Health A. 2007; 1;70(3-4): 227-42.

[13] http://epp.eurostat.ec.europa.eu

[14] Systematic Review of Health Aspects of Air Pollution in Europe. Copenhagen, Denmark, WHO Regional Office for Europe 2004

[15] Exposure of children to air pollution (particulate matter) in outdoor air. Copenhagen, WHO Regional Office for Europe 2009 (ENHIS fact sheet 3.3)

[16] Cohen A, Anderson H. The Global Burden of Disease Due to Outdoor Air Pollution. Journal of Toxicology and Environmental Health. 2005; 68:1301-1307 
[17] EEA 2010. The European Environment - State and outlook 2010: Synthesis. http://www.eea.europa.eu/soer/synthesis/synthesis

[18] Dockery, D, Pope C. A, Xu, X. An association between air pollution and mortality in six US cities. New England Journal for Medicine 1993; 329: 1753-1759

[19] Leksell I, Rabl A. Air Pollution and Mortality: Quantification and Valuation of Years of Life lost. Risk Anal. 2001; 21 (5):843-57

[20] Coyle D, Stieb D, Burnett RT, et al. Impact of particulate air pollution on quality-adjusted life expectancy in Canada. J Toxicol Environ Health A 2003; 66:1847-1863

[21] Krewski D. Evaluating the Effects of Ambient Air Pollution on Life Expectancy. N Engl J Med $2009 ; 360: 413-415$

[22] Craig L, Brook JR, Chiotti Q, et al. Air Pollution and Public Health: A Guidance Document for Risk Managers. J Toxicol Environ Health A 2008;71:588-698

[23] Brook RD. Cardiovascular effects of air pollution. Clin Sci (Lond). 2008; 115(6): 175-87

[24] http://www.who.int/mediacentre/factsheets/fs313/en/index.html

[25] Samoli E, Peng R, Ramsay T, et al. Acute effects of ambient particulate matter on mortality in Europe and North America: results from the APHENA study. Environ Health Perspect 2008;116:1480-6

[26] Puett R, Hart J, Yanosky J et al. Chronic Fine and Coarse Particulate Exposure, Mortality and Coronary Heart Disease in the Nurses' Health Study. Environ Health Perspect. 2009;117(11): 1702-1706

[27] Chen H, Goldberg MS, Villeneuve PJ. A systematic review of the relation between long-term exposure to ambient air pollution and chronic diseases. Rev Environ Health. 2008;23(4):243-97, 2008

[28] Zeger SL, Dominici F, McDermott A, Samet JM. Mortality in the Medicare population and chronic exposure to fine particulate air pollution in urban centers (2000-2005). Environ Health Perspect. 2008;116(12):1614-9

[29] ATS 2006 International Conference: Air Pollution Increases Mortality Risk.

[30] Elliott P, Shaddick G, Wakefield JC, et al. Long-term associations of outdoor air pollution with mortality in Great Britain. Thorax 2007; 62(12):1088-94

[31] World Health Organization Regional Office for Europe. European Heart Health Charter. 2007 (http:/ / www.heartcharter.org/)

[32] The European Heart Network. Annual Report 2009 fighting heart disease and stroke (http:/ / www.ehnheart.org/publications/annual-reports.html)

[33] http://www.who.int/mediacentre/factsheets/fs317/en/index.html

[34] http://www.allcountries.org/health/cardiovascular_diseases.html

[35] Brook RD, Rajagopalan S, Pope A, et al. Particulate Matter air Pollution and Cardiovascular Disease: An Update to the Scientific Statement From the American Heart Association. Circulation 2010; 121: 2331-2378

[36] Schwartz J. Is there harvesting association of airborne particles with daily deaths and hospital admissions? Epidemiology 2001; 12: 55- 61

[37] Franchini M, Mannucci PM. Short-term effects of air pollution on cardiovascular diseases: outcomes and mechanisms. J ThrombHaemost 2007;5:2169-2174

[38] Le Tertre A, Medina S, Samoli E, Forsberg B, Michelozzi P, Boumghar A, Vonk JM, Bellini A, Atkinson R, Ayres JG, SunyerJ,Schwartz J, Katsouyanni K. Short-term effects of particulate air pollution on cardiovascular diseases in eight European cities. J Epidemiol Community Health 2002; 56: 773-9

[39] Simkhovich B, Kleinman M, Kloner R. Air Pollution and Cardiovascular Injury. Journal of the American College of Cardiology 2008; 52 (9): 719-726 
[40] Miller KA, Siscovick DS, Sheppard L et al. Long-term exposure to air pollution and incidence of cardiovascular events in women. N EnglJ Med 2007 Feb 1;356(5):447-58

[41] Pope CA 3rd, Burnett RT, Thurston GD et al. Cardiovascular mortality and long-term exposure to particulate air pollution: epidemiological evidence of general pathophysiological pathways of disease. Circulation 2004 Jan 6;109(1): 71-7. Epub 2003 Dec 15

[42] Larrieu S, Jusot J-F, Blanchard M et al. Short term effects of air pollution on hospitalizations for cardiovascular diseases in eight French cities: The PSAS program. Science of the Total Environment 2007, 387: 105-112

[43] EU Department of Health. Cardiovascular Disease and Air Pollution. A Report by the Committee on the Medical Effects of Air Pollutants 2006

[44] Rankin J, Chadwick T, Natarajan M, Howel D, Pearce MS, Pless-Mulloli T. Maternal exposure to ambient air pollutants and risk of congenital anomalies. Environ Res 2009; 109: 181-187.

[45] Ricciardi C, Guastadisegni C. Environmental inequities and low birth weight. Ann Ist Super Sanita 2003; 39(2): 229-234.

[46] Liu S, Krewski D, Shi Y, Chen Y, Burnett RT. Association between gaseous ambient air pollutants and adverse pregnancy outcomes in Vancouver, Canada. Environ Health Perspect 2003; 111(14): 1773-1778.

[47] Wilhelm M, Ritz B. Residential proximity to traffic and adverse birth outcomes in Los Angeles county, California, 1994-1996. Environ Health Perspect 2003; 111(2): 207-216.

[48] Kasznia-Kocot J, Buszman Z. The influence of pollution on children's health in Chorzów. Pol J Environ Stud 1995; 4(2): 29-32.

[49] Salam MT, Millstein J, Li Y, Lurmann FW, Margolis HG, Gilliland FD. Birth outcomes and prenatal exposure to ozone, carbon monoxide and particulate matter: results from the children's health study. Environ Health Perspect 2005; 113(11): 1638-1644.

[50] Barakat AO. PAHs and petroleum biomarkers in the atmospheric environment of Alexandria City, Egypt. Water Air Soil Pollut 2002; 139: 289- 310.

[51] Perera F.P., Whyatt R.M., Jędrychowski W., et al. A study of the effects of environmental polycyclic aromatic hydrocarbons on birth outcomes in Poland. Am J Epidemiol 1998; 147: 309-314.

[52] Perera F.P., Rauh V., Tsai W.Y., et al. Effects of transplacental exposure to environmental pollutants on birth outcomes in a multi-ethnic population. Environ Health Perspect 2003; 111: 201-205.

[53] Dejmek J., Solansky I., Benes I., et al. The impact of polycyclic aromatic hydrocarbons and fine particles on pregnancy outcome. Environ Health Perspect 2000; 108: 1159-1164.

[54] Sram R.J., Binkova B., Rossner P., et al. Adverse reproductive outcomes from exposure to environmental mutagens. Mutat Res 1999; 428: 203-215.

[55] Topinka J., Binkova B., Stavkova Z., et al. DNA adducts in human placenta as related to air pollution and to GSTM1 genotype. Mutat Res 1997; 390: 59-68.

[56] Boy E, Bruce N, Delgado H. Birth weight and exposure to kitchen wood smoke during pregnancy in rural Guatemala. Environ Health Perspect 2002; 110(1): 109-114.

[57] Dejmek J, Selevan SG, Benes I, Solansky I, Sram RJ. Fetal growth and maternal exposure to particulate matter during pregnancy. Environ Health Perspect 1999; 107(6): 475-480.

[58] Chen L, Yang W, Jennison BL, Goodrich A, Omaye ST. Air pollution and birth weight in Northern Nevada, 1991-1999. Inhal Toxicol 2002; 14: 141-157.

[59] Wang X, Ding H, Ryan L, Xu X. Association between air pollution and low birth weight: a community-based study. Environ Health Perspect 1997; 105(5): 514-520. 
[60] Rogers JF, Thompson SJ, Addy CL, McKeown RE, Cowen DJ, Decoufle P. Association of very low birth weight with exposure to environmental sulphur dioxide and total suspended particulates. Am J Epidemiol 1999; 151(6): 602-613.

[61] Gouveia N, Bremner SA, Novaes HDM. Association between ambient air pollution and birth weight in Sao Paulo, Brazil. J Epidemiol Community Health 2004; 58: 11-17.

[62] Jędrychowski W, Bendkowska I, Flak E, et al. Estimated risk for altered fetal growth resulting from exposure to fine particles during pregnancy: an epidemiologic prospective cohort study in Poland. Environ Health Perspect 2004; 112(14): 1398-1402.

[63] Parker JD, Woodruff TJ, Basu R, Schoendorf KC. Air pollution and birth weight among trem infants in California. Pediatrics 2005; 115(1): 121-128.

[64] Brauer M, Lencar C, Tamburic L, Koehoorn M, Demers P, Karr C. A cohort study of traffic-related air pollution impacts on birth outcomes. Environ Health Perspect 2008; 116(5): 680-686.

[65] Ballester F, Estarlich M, Iniguez C, et al. Air pollution exposure during pregnancy and reduced birth size: a prospective birth cohort study in Valencia, Spain. Environ Health 2010; 9(6).

[66] Maroziene L, Grazuleviciene R. Maternal exposure to low-level air pollution and pregnancy outcomes: a population-based study. Environ Health 2002; 1(6).

[67] Currie J, Neidell M, Schmieder JF. Air pollution and infant health: Lessons from New Jersey. J Health Econ 2009; 28: 688-703.

[68] Szeszenia-Dąbrowska N., Sobala W. Environmental pollution by asbestos. Health effects. The Nofer Institute of Occupational Medicine. ISBN 978-83-923517-5-7, Lodz, 2010.

[69] IARC Monographs, Vol. 14, 1977.

[70] Krakowiak E, Górny R, Cembrzyńska J, Sąkol G, Boissier-Draghi M, Anczyk E. Environmental Exposure to Airborne Asbestos Fibres in a Highly Urbanized City. Ann Agric Environ Med, 16, 121-128, 2009.

[71] Bignon J., Sebastien P., di Menza L., Nebut M., Payan H. French registry of mesotheliomas 1965-1978. Rev Fr Mal Respir, 7, 223-242, 1979.

[72] Enterline P.E. Cancer produced by nonoccupational asbestos exposure in the United States. J Air Pollution Control Assoc., 33, 318-322, 1983.

[73] Saracci R. Asbestos and lung cancer: an analysis of the epidemiological evidence on the asbestossmoking interaction. Int J Cancer, 20, 323-331, 1977.

[74] WHO, Special Report: Elimination of asbestos - related diseases, 2006.

[75] Currie G, Watt S, Maskell N. Reconstruction of Moscow: allergy, dust, asbestos and other medical aspects. BMJ, 339, 2009.

[76] Więcek E. Asbestos-exposure and health effects. Work Safety, 2, 2004.

[77] Jawecki B. Programming asbestos removal at the local level - a proposal guidlines. Infrastructure and Ecology of Rural Areas. Polish Academy of Sciences, Krakow, 9, 7383, 2008.

[78] Łuniewski A, Łuniewski S. Asbestos-historical burden of the 20 th century. Publishing house of Environmental and Resources Economists. ISBN 978-83-61643-28-9, Białystok, 2008.

[79] Kazan-Allen L. Asbestos and mesothelioma: Worldwide trends. Lung Cancer, 49, 3-8, 2005.

[80] Vogel L. Special Report - Asbestos in the world. HESA, 2005. 


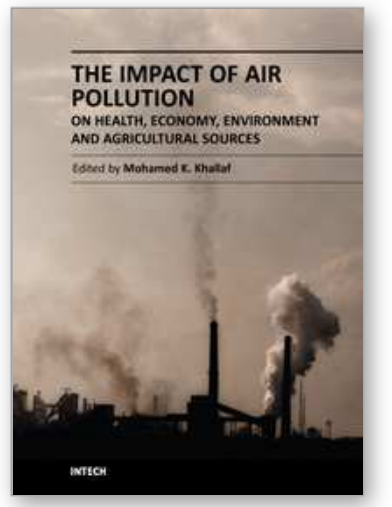

\author{
The Impact of Air Pollution on Health, Economy, Environment and \\ Agricultural Sources \\ Edited by Dr. Mohamed Khallaf
}

ISBN 978-953-307-528-0

Hard cover, 444 pages

Publisher InTech

Published online 26, September, 2011

Published in print edition September, 2011

This book aims to strengthen the knowledge base dealing with Air Pollution. The book consists of 21 chapters dealing with Air Pollution and its effects in the fields of Health, Environment, Economy and Agricultural Sources. It is divided into four sections. The first one deals with effect of air pollution on health and human body organs. The second section includes the Impact of air pollution on plants and agricultural sources and methods of resistance. The third section includes environmental changes, geographic and climatic conditions due to air pollution. The fourth section includes case studies concerning of the impact of air pollution in the economy and development goals, such as, indoor air pollution in México, indoor air pollution and millennium development goals in Bangladesh, epidemiologic and economic impact of natural gas on indoor air pollution in Colombia and economic growth and air pollution in Iran during development programs. In this book the authors explain the definition of air pollution, the most important pollutants and their different sources and effects on humans and various fields of life. The authors offer different solutions to the problems resulting from air pollution.

\title{
How to reference
}

In order to correctly reference this scholarly work, feel free to copy and paste the following:

E. Marchwinska-Wyrwal, G. Dziubanek, I. Hajok, M. Rusin, K.Oleksiuk and M.Kubasiak (2011). Impact of Air Pollution on Public Health, The Impact of Air Pollution on Health, Economy, Environment and Agricultural Sources, Dr. Mohamed Khallaf (Ed.), ISBN: 978-953-307-528-0, InTech, Available from: http://www.intechopen.com/books/the-impact-of-air-pollution-on-health-economy-environment-andagricultural-sources/impact-of-air-pollution-on-public-health

\section{INTECH}

open science | open minds

\section{InTech Europe}

University Campus STeP Ri

Slavka Krautzeka 83/A

51000 Rijeka, Croatia

Phone: +385 (51) 770447

Fax: +385 (51) 686166

www.intechopen.com

\section{InTech China}

Unit 405, Office Block, Hotel Equatorial Shanghai

No.65, Yan An Road (West), Shanghai, 200040, China

中国上海市延安西路65号上海国际贵都大饭店办公楼 405 单元

Phone: +86-21-62489820

Fax: +86-21-62489821 
(C) 2011 The Author(s). Licensee IntechOpen. This chapter is distributed under the terms of the Creative Commons Attribution-NonCommercialShareAlike-3.0 License, which permits use, distribution and reproduction for non-commercial purposes, provided the original is properly cited and derivative works building on this content are distributed under the same license. 